\title{
PELATIHAN KEWIRAUSAHAAN PEMBUATAN NATA DE COCO
}

\author{
Harianingsih , Suwardiyono, Maharani Kusumaningrum \\ Jurusan Teknik Kimia, Fakultas Teknik, Universitas Wahid Hasyim \\ Jl. Menoreh Tengah X/22, Sampangan, Semarang 50236. \\ *Email: harianingsih@unwahas.ac.id
}

\begin{abstract}
Abstrak
Pengangguran dari tahun ke tahun marak menjadi masalah yang masih perlu penyelesaian. Rendahnya serapan lapangan pekerjaan bagi lulusan perguruan tinggiyang rendah, sementara lulusan perguruan tinggi sangat banyak. Persaingan yang semakin ketat ini menyebabkan lulusan susah memperoleh pekerjaan. Kondisi inilah yang menyebabkan para lulusan perguruan tinggi untuk dapat menciptakan lapangan pekerjaan. Pembelajaran yang diberikan pada perguruan tinggi diharapkan mendorong mahasiswa untuk mempunyai kemampuan berwirausaha. Untuk menumbuhkan jiwa kewirausahaan pada mahasiswa maka dilakukanlah pelatihan kewirausahaan pembuatan nata de coco. Nata de coco merupakan penerapan ilmu bioproses yang mereka dapatkan di perguruan tinggi khususnya jurusan Teknik Kimia Universitas Wahid Hasyim Semarang. Pada pelatihan nata de coco ini diikuti oleh tujuh orang mahasiswa yang mewakili angkatan masing-masing. Harapannya agar mereka dapat mentransfer ilmu dan keterampilan membuat nata de coco kepada orang lain dan masyarakat di sekitarnya.
\end{abstract}

Kata kunci: coco, nata, wirausaha

\section{PENDAHULUAN}

Perguruan tinggi saat ini dituntut menciptakan lulusan yang tidak hanya baik dalam hal akademisi tetapi juga mempunyai kemampuan untuk menciptakan lapangan pekerjaan dan berwirausaha. Salah satu metode yang dilakukan adalah dengan memeberikan pelatihan. Pelatihan kewirausahaan yang diberikan di Jurusan Teknik Kimia Universitas Wahid Hasyim semarang adalah Pelatihan pembuatan Nata de coco.

Nata de coco merupakan jenis makanan hasil teknologi bioproses fermentasi oleh bakteri Acetobacter xylinum. Acetobacter xylinum dalam pertumbuhan dan aktivitasnya membentuk nata memerlukan suatu media yang tepat memiliki kandungan komponen-komponen yang dibutuhkan sehingga produksi nata yang dihasilkan dapat secara optimal. Komponen media nata yang dibutuhkan sebagai syarat media nata antara lain memiliki sumber karbon dapat berupa gula, sumber nitrogen dapat berupa penambahan urea atau ZA, mineral dan vitamin yang mendukung pertumbuhan bakteri acetobacter xylinum. Pada fermentasi nata kondisi lingkungan juga sangat berpengaruh karena bakteri acetobacter xylinum memiliki kondisi optimum lingkungannya untuk tumbuh baik itu suhu, $\mathrm{pH}$, cahaya, oksigen dan lain-lainnya (Harianingsih, 2016).

Nata adalah produk fermentasi oleh bakteri Acetobacter xylinum pada substrat yang mengandung gula. Bakteri tersebut menyukai kondisi asam dan memerlukan nitrogen untuk stimulasi aktifitasnya. Glukosa substrat sebagian akan digunakan bakteri untuk aktifitas metabolisme dan sebagian lagi diuraikan menjadi suatu polisakarida yang dikenal dengan "extracelluler selulose" berbentuk gel. Polisakarida inilah yang dinamakan nata. Proses pembuatan nata dipengaruhi oleh ketersediaan nutrisi, derajat keasaman, temperature dan ketersediaan oksigen. Bahan baku stater dapat digunakan nanas karena nanas merupakan sumber Acetobacter xylinum yang terbanyak (Harianingsih, 2017).

Nata de coco ialah sejenis makanan fermentasi yang dibuat dengan bahan dasar air kelapa. Nata tersusun dari senyawa yang dihasilkan oleh bakteri Acetobacter xylinum. Acetobacter xylinum dapat hidup dalam air kelapa dan juga dalam buah- 
buahan yang mengandung glokosa dalam cairan buah nenas, yang kemudian diubah menjadi selulose dan dikeluarkan ke permukaan sel. Lapisan selulosa ini terbentuk selapis demi selapis pada permukaan sari buah, sehingga akhirnya menebal inilah yang disebut nata. (Harianingsih, 2017). Nata terbentuk dari aktivitasbakteri Acetobacter xylinum dalam sari buah yang mengandung glukosa yang kemudian diubah menjadi asam asetat dan benang-benang selulosa. Lama-kelamaan akan terbentuk suatu massa yang kokoh dan mencapai ketebalan beberapa sentimeter. Selulosa yang dikeluarkan ke dalam media itu berupa benang-benang yang bersamasama dengan polisakarida berlend membentuk jalinan yang terus menebal menjadi lapisan nata. Bakteri Acetobacter xylinum akan dapat membentuk nata jika ditumbuhkan dalam air kelapa yang sudah diperkaya dengan Karbon (C) dan Nitrogen $(\mathrm{N})$, melalui proses yang terkontrol. Dalam kondisi demikian, bakteri tersebut akan menghasilkan enzim akstraseluler yang dapat menyusun zat gula menjadi ribuan rantai serat atau selulosa (Harianingsih, 2017).

\section{METODOLOGI}

\section{Bahan :}

Bahan (resep untuk hasil $1 \mathrm{~kg}$ nata), air kelapa untuk pembibitan stater sebanyak 1 liter. 1 liter air Air kelapa, 3 sendok makan gula pasir, 3 sendok teh asam asetat (cuka dapur), 1 sendok teh ZA/urea, $100 \mathrm{ml}$ (1/2 gelas) stater

\section{Alat:}

Loyang, Kertas koran, karet, Panci, Kompor, Pengaduk, Toples kaca

\section{Prosedur Kerja \\ Pembuatan Bibit/ Stater}

Proses perbanyakan dilakukan dengan memanaskan air kelapa sebanyak 1 liter kemudian dipanaskan dan ditambahkan 3 sendok makan gula pasir, 3 sendok the asam asetat, 1 sendok the ZA kemudian didihkan. Setelah dingin dimasukkan dalam 2 botol kaca kemudian stater dituang sebanyak $100 \mathrm{ml}$.

\section{Pembuatan Nata de Air kelapa}

Panaskan air air kelapa , tambahkan 3 sendok makan gula pasir, 3 sendok teh cuka, 1 sendok teh ZA/urea, aduk sampai mendidih, masukkan ke dalam loyang, dinginkan, masukkan $100 \mathrm{ml}$ stater, tutup dengan kertas koran, fermentasi selama 7 hari hingga terbentuk lembaran nata, cuci lembaran nata dengan air mengalir, potong dadu dan rebus sampai mendidih, ganti air rebusan, rebus kembali sampai mendidih dan tambahkan essence (perisa) jika perlu, Nata de coco siap dihidangkan.

\section{PEMBAHASAN}

Pelatihan pembuatan nata de coco diikuti oleh 7 peserta yang dipilih dari perwakilan setiap angkatan mahasiswa Teknik Kimia Universitas Wahid Hasyim Semarang, dengan harapan dapat mempelajari kemudian menularkan proses pembelajaran kepada teman di angkatan masing-masing. Beberapa proses selama kegiatan berlangsung dapat dilihat pada Gambar 1 sampai dengan 5. Pada gambar 1 diperlihatkan proses presentasi proses embuatan nata de coco. Peserta sangat antusias dalam mengikuti pelatihan ini. Metode yang dilakukan adalah experimental learning jadi selain presentasi juga ditunjukkan secara langsung bahan-bahan yang digunakan, alat kemudian proses pembuatan nata de coco dari pembibitan hingga produksi nata.

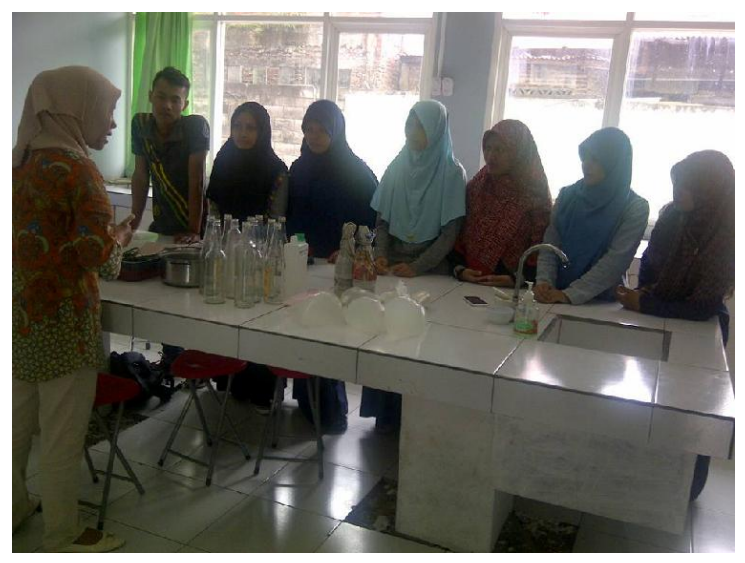

Gambar 1. Presentasi Bahan, Alat, Metode Pembuatan Nata de Coco 
Proses pembibitan dilakukan untuk memperbanyak stater. Stater merupakan unsur penting dalam pembuatan nata de leri. Stater merupakan populasi bakteri acetobacter xylinum yang bertugas membentuk serat selulosa. Pembuatan stater dilakukan dengan cara menghaluskan nanas menggunakan blender. Pemanfaatan buah nanas dikarenakan nanas banyak mengandung acetobacter xylinum. Pembibitan dilakukan dengan membuat mendidihkan air kelapa, ditambahkan dengan gula pasir dan ZA kemudian diaduk. Setelah mendidih tambahkan asam asetat kemudian aduk dan matikan kompor. Penambahan gula pasir bertujuan untuk sumber karbon, penambahan ZA untuk sumber nitrogen dan penambahan asam asetat untuk pengaturan $\mathrm{pH}$ agar $\mathrm{pH}$ antara 3-4. Larutan dimasukkan ke dalam botol kaca ukuran $600 \mathrm{ml}$ dan stater dituang setelah larutan dingin, kemudian ditutup dan disimpan pada ruang gelap dan suhu kamar (Harianingsih, 2016).

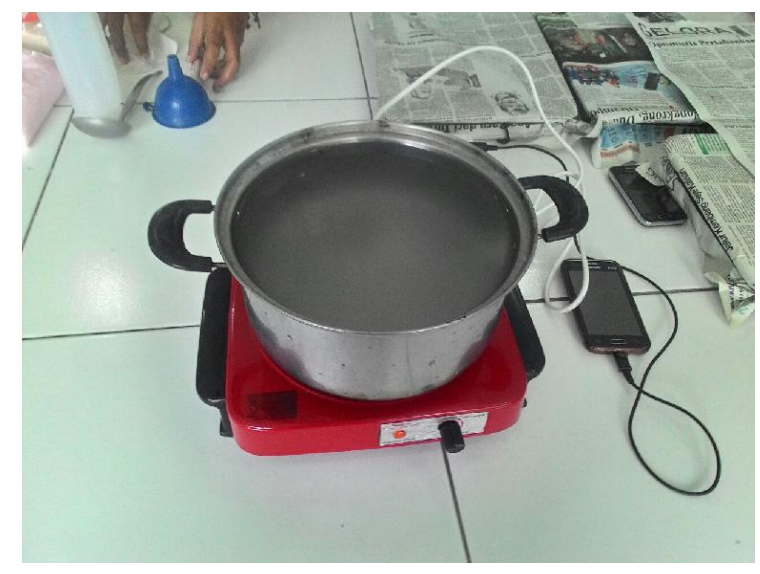

\section{Gambar 2. Pemasakan Bahan Baku Air Kelapa}

Pada gambar 2. Diperlihatkan proses pemasakan air kelapa. Air kelapa dipilih sebagai bahan baku karna media yang paling tepat digunakan untuk pertumbuhan Acetobacter xylinum. Proses pemanasan dilakukan selama kurang lebih 30 menit dengan suhu pemanasan sebesar $70{ }^{\circ} \mathrm{C}$.

Pada gambar 3. Merupakan proses penuangan gula pasir sebanyak tiga sendok makan, ZA sebanyak satu sendok teh dan asam asetat sebanyak tiga sendok the.

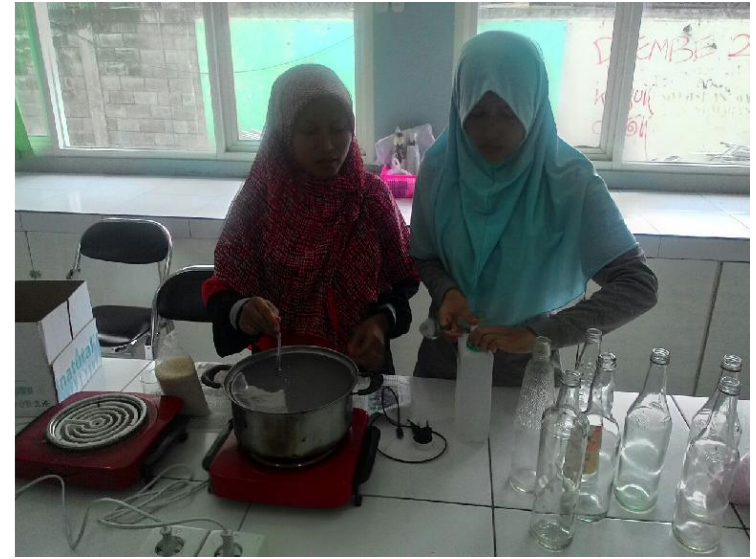

Gambar 3. Penuangan Gula Pasir, ZA, Asam Asetat

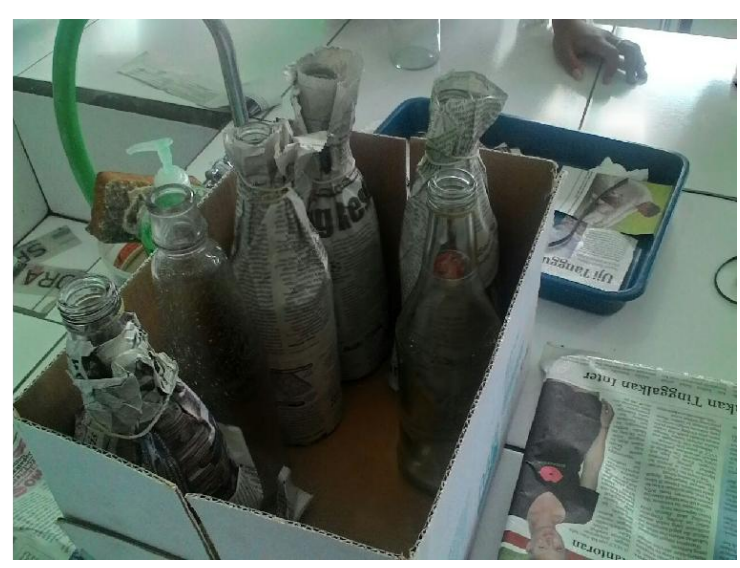

\section{Gambar 4. Pembibitan}

Pada gambar 4. Merupakan cara pembibitan stater Acetobacter xylinum. Stater yang terbuat dari nanas diperbanyak menggunakan media air kelapa kemudian difermentasi menggunakan botol yang ditutup dengan koran. Penggunaan botol karena menggunakan botol stater yang terbentuk cairan dapat digunakan dalam jangka waktu yang lebih lama. Sedangkan koran digunakan untuk membuat kondisi botol tidak terkena cahaya matahari (gelap) karena Acetobacter xylinum dapat tumbuh baik jika tidak terkena cahaya matahari secara langsung.

Pada proses pembuatan nata de coco sama dengan pembibitan akan tetapi air kelapa dan larutan dituang dalam loyang kemudian ditutup dengan kertas Koran dan diletakkan dalam ruangan dengan suhu kamar. Penggunaan Loyang yang dapat kita lihat pada gambar 5 . bertujuan agar diperoleh nata de coco yang berbentuk lembaran sehingga mudah dipotong sesuai dengan keinginan saat pengemasan nantinya. 


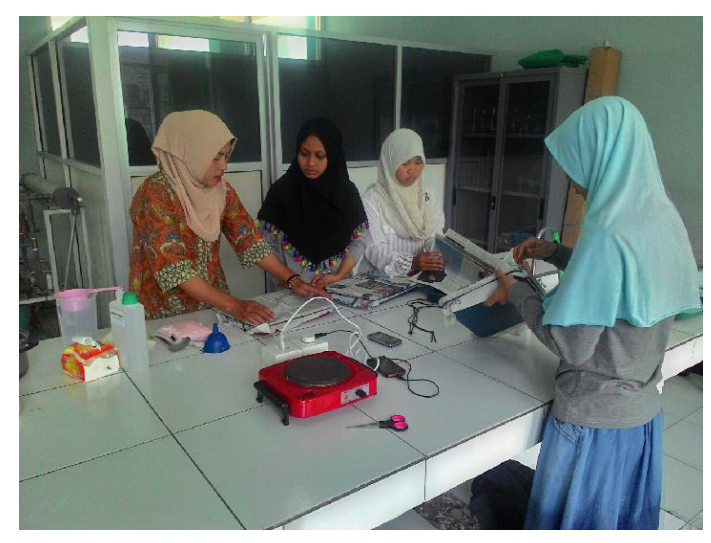

\section{Gambar 5. Persiapan Loyang untuk Fermentasi}

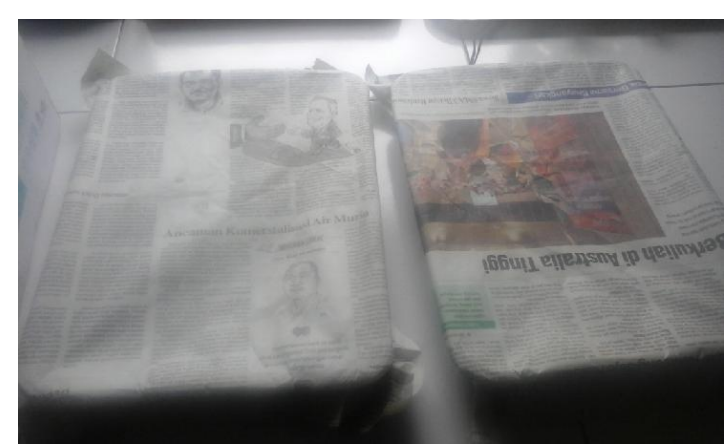

\section{Gambar 6. Fermentasi}

Gambar 6. Memperlihatkan proses fermentasi nata de coco. Fermentasi dilakukan selama tujuh hari. Kondisi prodses fermentasi yang diinginkan adalah pada suhu kamar yaitu 25$32^{\circ} \mathrm{C}$ dan $\mathrm{pH} 3-5$. Kondisi tersebut merupakan kondisi yang paling baik untuk pertumbuhan Acetobacter xylinum.

\section{KESIMPULAN}

1. Pelatihan kewirausahaan di perguruan tinggi diperlukan untuk menciptakan lulusan yang dapat menciptakan lapangan pekerjaan.

2. Metode pelatihan kewirausahaan nata de coco yang dilakukan experimental learning yaitu presentasi dan praktik langsung.

3. Peserta terdiri dari tujuh mahasiswa yang mewakili tiap angkatan.

\section{SARAN}

Pelatihan kewirausahaan tidak hanya sampai dengan pembuatan produk nata de coco, tetapi juga diberikan pelatihan lanjutan antara lain pelatihan pengemasan dan pelatihan pemasaran.

\section{DAFTAR PUSTAKA}

Harianingsih dan Claudia Harliyanto. (2016). Pemanfaatan Sagu Sebagai Bahan Pembawa (Carrier) Pada Kristalisasi Gluconano Acetobacter. Jurnal Inovasi Teknik Kimia Vol 1 No. 1. Hal. 45-49.

Harianingsih, dkk. (2016). Pemberdayaan Ibu Rumah Tangga Melalui Pelatihan Pembuatan Nata De Leri di Kelurahan Banyumanik Semarang.Jurnal Abdimas Unwahas. Vol 1. No. 1. Hal. 17-22.

Harianingsih dan Suwardiyono. (2017). Pengaruh Penambahan Gliserol terhadap Tensile Strenght dan Elongation Break Edible Film dari Nata de Soya. Jurnal Inovasi Teknik Kimia Vol 2. No. 1. 